\title{
SOBRE A DIVULGAÇÃO DO SISTEMA INDO-ARÁBICO NA EUROPA NO SÉCULO XIII
}

\section{ON DISSEMINATION OF THE INDO-ARABIC SYSTEM IN EUROPE IN THE 13th CENTURY}

\author{
José dos Santos Guimarães Filho ${ }^{1}$ \\ Universidade Federal do Pará \\ João Cláudio Brandemberg ${ }^{2}$ \\ Universidade Federal do Pará
}

\begin{abstract}
Resumo
Nesta comunicação apresentamos alguns pontos que nos permite de forma preliminar investigar sobre a divulgação dos algarismos indo-arábicos na Europa no século XIII, afinal, estes se constituem ao longo da história humana como um sistema universal. Com a finalidade de evocar os possíveis fatos que fizeram os algarismos indo-arábicos terem tamanho sucesso. Para tanto, fizemos uma pesquisa bibliográfica, na qual, obtivemos informações, no que tange, a uma construção histórica do cenário propício para a divulgação dos algarismos indo-arábicos, evidenciando alguns pontos que julgamos importantes para esse momento. Nessa busca encontramos autores como Potro (2000) e Vasconcelos (1925); Garbi (2007) entre outros. A partir desses autores podemos perceber alguns fatos interessantes, como a ruptura do Império Romano, o dividindo, em parte Oriental e parte Ocidental, o que ocasionou desenvolvimentos diferentes, sejam estes, políticos, culturais, sociais, religiosos, econômicos e científico. Estas duas partes passaram por períodos de obscuridade científica, pois vivenciaram intensos momentos de guerra, no entanto, o Ocidente, consegue de forma mais tardia seu desenvolvimento científico, deixando para o Oriente a responsabilidade de reerguer um novo centro científico, este centro, chamado de Casa da Sabedoria, foi instalado em Bagdá no período de califado, permitido o crescimento posterior da Europa, bem como, de viajantes como Leonardo Fibonacci $(1180$ - 1250), que iam para o Oriente afim de conhecer a aritmética prática e comercial. Podemos verificar que o fator principal para o êxito na divulgação de Leonardo Fibonacci, não foi o brilhantismo de seu Liber Abaci, mas sim, o cenário de estabilidade social, econômico, cultural e político, o que proporcionou o momento adequado para sua obra.
\end{abstract}

Palavras-chave: Sistema numérico decimal posicional; Liber Abaci; Aritmética comercial; Aritmética prática.

1 is_guima@hotmail.com

2 brand@ufpa.br

Número Especial - IV Seminário Cearense de História da Matemática

Boletim Cearense de Educação e História da Matemática - Volume 07, Número 20, 380 - 391 (2020)

DOI: $10.30938 /$ bocehm.v7i20.2843 


\begin{abstract}
In this communication we present some points that allow us to preliminary investigate the dissemination of Indo-Arabic numerals in Europe in the thirteenth century, after all, these constitute throughout human history as a universal system. In order to evoke the possible facts that made the Indo-Arabic numerals so successful. For such, we made a bibliographic research, in which, we obtained overwhelming information, regarding, to a historical construction of the propitious scenario for the dissemination of the IndoArabic numerals, highlighting some points that we considered important for this moment. In this search we find authors such as Potro (2000) and Vasconcelos (1925); Garbi (2007) among others. From these authors we can see some interesting facts, such as the rupture of the Roman Empire, dividing it, in eastern and western parts, which led to different developments, whether political, cultural, social, religious, economic and scientific. These two parts went through periods of scientific obscurity, because they experienced intense moments of war, however, the West, later achieves its scientific development, leaving to the East the responsibility of rebuilding a new scientific center, this center, called House of Wisdom, was installed in Baghdad during the caliphate period, allowed the later growth of Europe, as well as travelers like Leonardo Fibonacci (1180 - 1250), who went to the East to know the practical and commercial arithmetic. We can see that the main factor for Leonardo Fibonacci's successful dissemination was not the brilliance of his Liber Abaci, but the scenario of social, economic, cultural and political stability, which provided the right moment for his work.
\end{abstract}

Keywords: Positional decimal number system; Liber Abaci; Commercial Arithmetic; Practical Arithmetic.

\title{
Introdução
}

O uso dos algarismos indo-arábicos é algo comum em quase todos os países, sendo adotados ao longo da história humana como um sistema universal. Estes algarismos e o sistema numérico decimal e posicional, apresentam muitas vantagens em relação a outros sistemas e outros algarismos, facilitando muitas atividades práticas, como foi o comércio.

Podemos por assim dizer, que este sistema e estes numerais, revolucionaram de alguma forma as sociedades que os adotaram. No entanto, esse trajeto não foi simples e nem rápido, foi lento e muito complexo. Dessa maneira, nesta comunicação, apresentamos de forma preliminar, uma pesquisa, que aponta para algumas questões: Qual sua origem? Como se deu esta implementação? Quais fatores permitiram o êxito desses algarismos e do sistema numérico decimal posicional? Muito embora, pareça questões de simples verificação, percebemos que uma construção epistemológica, que possa responder a tais questionamentos, não é trivial, valendo ressaltar que este texto faz parte de uma pesquisa preliminar. 
Objetivamos dessa forma, tecer uma construção histórica evidenciando alguns pontos que julgamos importantes para esse momento, afim, de evocar os possíveis fatos que fizeram os algarismos indo-arábicos terem tamanho sucesso na Europa no século XIII. Para tanto, fizemos uma pesquisa bibliográfica que pudesse apresentar informações satisfatórias, que nos permitissem ir ao encontro de nossos questionamentos.

Assim, apresentamos primeiramente o cenário do Oriente e do Ocidente antes de 1202, ano este, que Leonardo Fibonacci (1180 - 1250) escreve e publica o Liber Abaci, marco da implementação dos algarismos indo-arábicos na Europa. Ao apresentar a ruptura do Império Romano em parte Oriental e Ocidental, apresentamos o contraste destas duas regiões. E posteriormente o cenário no início do século XIII.

\section{Antes de 1202}

Ao falar da Europa antes de 1202, optamos por evidenciar o cenário vizinho, o Oriente, dessa forma, iniciamos nossa escrita apresentando este cenário e suas contribuições para o continente Europeu, para que haja uma elucidação das influências recebidas pela ciência construída por esses vizinhos, sobretudo, as circunstâncias para a inserção dos algarismos ou cifras indianas na Europa.

\section{O Oriente}

Garbi (2009) ao apresentar um pouco desse cenário, esclarece que embora o Império Romano tenha atingido seu apogeu no século II, a corrupção interna e a tomada das fronteiras pelos bárbaros, ocasionou a ruptura do Império em parte Ocidental e parte Oriental. Olhando para parte oriental, a qual, foi onde a cultura acumulada da antiguidade clássica sobreviveu por séculos, esta apresenta indícios de como a conservação do conhecimento ajudou no progresso da ciência na parte ocidental.

Não obstante, essa parte oriental passa por um período obscuro para os avanços na matemática e para outras ciências, pois Abul Alcacim Maomé ibne Abdalá ibne Abdal Mutalibe ibne Haxim, comumente conhecido como Maomé (571 - 632), é engajado como um líder militar e religioso influente, tornando-se mentor de várias guerras, que mesmo com sua morte no ano de 632, os seus seguidores permaneceram determinados na expansão islâmica atingindo Alexandria no ano de 641, ocasionando a 
destruição de sua biblioteca, que por muitos é considerado, nessa ocasião, como o centro matemático do mundo.

Com essa destruição, com guerras que duraram mais de um século, e com os árabes lutando entre si e com seus inimigos, não houve muitas oportunidades para o desenvolvimento intelectual e cultural. Ainda assim, no ano de 750 esse calor de guerras esfriou e sobre o governo do califa Al-Mansur (714 - 775) é estabelecido uma nova capital em Bagdá as margens do rio Tigre que posteriormente se transformaria em um novo centro matemático, uma nova Alexandria (BOYER, 1974). Al-Mansur consegue atrair para Bagdá sábios de várias regiões, incluindo judeus e cristãos, neste momento de reconstrução do conhecimento, este califa em 773 recebe em sua corte uma delegação de astrônomos e matemáticos hindus, os quais, explicaram a Al-Mansur, bem como, aos seus eruditos como trabalhar com o sistema Indiano de numeração, sendo adotado pelos sábios de Bagdá (GARBI, 2009).

Neste momento de califado, em conformidade com Garbi (2009), temos um fato importante que anos mais darde contribuiria para a Europa como fonte de estudo, este fato foi as traduções feitas para o árabe dos Elementos de Euclides intermediada pelo califa Harun Al-Rashid (763 - 809), o qual ficou mais conhecido pelos contos de mil e uma noites. Seu sucessor, Al-Mamun (786 - 833), foi um dos califas que também prestigiou a cultura e o conhecimento, este estabeleceu em Bagdá uma Casa da Sabedoria (Bait al-hikma), que é comparável ao museu de Alexandria.

Entre esses mestres que havia ali, estava Mohammed Ibu-Musa Al-khowarizmi ou mais conhecido como Al-khowarizmi ${ }^{3}(780-850)$, o seu nome torna-se familiar na Europa Ocidental, assim como o de Euclides. Este matemático e astrônomo era, na verdade, de acordo com Garbi (2007), um persa, nascido em Khwarezm (uma província Persa, hoje chamada Khiva), que viveu em Bagdá e nasceu por volta de 780. Alkhowarizmi produz alguns materiais de astronomia e matemática, além de tabelas astronômicas, tratados do astrolábio e relógio do sol. Escreveu ainda, dois livros sobre aritmética e álgebra que, de acordo com Boyer (1974) tiveram um desempenho importante na História da Matemática e morre algum tempo antes de 850.

Tendo-lhe sido solicitado por Al-Mamun que produzisse uma obra popular sobre as equações, ele escreveu o livro Hisab Al-jabr Wa'l Muqãbalah,

\footnotetext{
${ }^{3}$ O seu nome dá origem a palavra algoritmo e a tradução do seu nome completo segundo Eves (2011) é
} Maomé, filho de Moisés de Khwarezm. 
título que pode ser traduzido por "O Livro da Restauração e do Balanceamento". A palavra $\boldsymbol{A l - j a b r}$ era empregada dor Al-Khwarizmi para designar operações em que, por exemplo, a equação $x-3=6$ passa a ser $x=9$, significando uma restauração de $x-3$ de modo a torna-se a incógnita completa $x$. Foi assim que nasceu a palavra Álgebra, presente em todos os idiomas do planeta, tão empregada na matemática e que está claramente relacionada às noções comuns de Euclides (GARBI, 2009, p. 24, grifos do autor).

Al-Khwarizmi também escreveu neste livro as cifras indianas, onde, apresenta a noção posicional na base dez, assim como, o numeral zero. Neste livro é trabalhado com afinco as regas necessárias para operar com este novo sistema de numeração (POTRO, 2000). Outro livro importante deste matemático é o Kitab al-jami wa'l tafriq bi hisab al hindi que segundo Garbi (2009), pode ser traduzido como Livro sobre o método hindu de adição e subtração, o qual, de igual forma apresenta as cifras indianas incluindo o zero, no entanto, com uma preocupação a mais, pensando em popularizar o sistema hindu de numeração decimal, buscou simplificar a simbologia. Isso permitiu que em algumas décadas, esse sistema de numeração estivesse em uso comum pelo povo, em particular, pelos comerciantes.

A ciência deve muito a este momento de califado, pois com o intuito, também, de propagar a cultura árabe pelo mundo, é que foi preservado muitos conhecimentos, a partir de várias traduções de livros para o árabe, como o Almagesto de Ptolomeu e os Elementos de Euclides já citado. Desta forma, graças a esses califas e aos esforços, no que tange, ao censo de futuro e de preservação da cultura, foi possível para Europa usufruir deste conhecimento anos mais tarde (SANTOS, 2009).

O câmbio deste conhecimento inicia com os comerciantes, que em conformidade com Garbi (2009),

Foi na extensa fronteira entre os mundos cristão e muçulmano que os europeus, realizando transações comerciais com os árabes, tiveram seus primeiros contatos com um outro tipo de Aritmética. A obra de Al-khwarizmi exerceu grande influência na matemática europeia durante os últimos séculos da idade média (GARBI, 2009, p. 24).

\section{O Ocidente}

Olhando para a parte Ocidental, observamos após o século III a ruptura da matemática medieval com a grega da antiguidade, a qual, Brito (2007) apresenta alguns aspectos, como a ruptura linguística do Ocidente com o Oriente. Temos, também, que a 
cultura Romana optava por técnicas tradicionais de medidas e contagem que eram necessários ao cadastro do império, bem como, pela geometria pura. Outra questão que pode ser apontada, é no papel da igreja católica no que se refere à produção, veiculação e manutenção das ideias e saberes, passando a ser uma exclusividade do clero o acesso ao conhecimento já existente, assim como, sua produção, haja vistas, ser de domínio do clero a leitura e a escrita (BRITO, 2007).

Desta forma, no século VI e VII temos, de forma principal, a construção de manuais, o estudo e o ensino dos saberes já produzidos, o que nos remete ao fato de que, a maior parte das obras nesse período eram traduções parciais feitas de textos já existentes (BRITO, 2007). Das quais, Anicio Manlio Severino Boécio (480 - 524) foi um dos destaques dessas traduções, o qual, é citado por Vasconcelos (1925) como o último grande romano, ocupando lugar importante na história das matemáticas, pois a partir de seus livros é que a Europa obteve o conhecimento científico do mundo antigo, oportunizando o conhecimento da geometria e da aritmética.

Sob o ponto de vista matemático, tanto a Aritmética como a Ars Geometriae são livros de diminuto valor. Durante vários séculos constituíram, porém, a base de todo o ensino matemático na Escolas das catedrais e dos conventos da Europa Ocidental, e, juntamente com os livros de outro romano, Cassiodoro (490 - 566), e de Isidoro, Bispo de Sevilha (570 - 636), consagrados ao quadrivium matemático - aritmética, geometria, música e astronomia - foram considerados obras modelo (VASCONCELOS, 1925, p. 545-546, grifos do autor).

Em conformidade com Vasconcelos (1925), é de Boécio a designação Quadrivium à estrutura que dividia a posterior matemática, já designada dessa forma, por Isidoro e Cassiodoro. Assim, havia o estudo das quantidades discretas e contínuas, ou segundo Boécio, o estudo das quantidades e grandezas imóveis (Aritmética e Geometria) e o estudo das quantidades e magnitudes móveis (Música e Astronomia), ou seja, números e figuras em movimento (BRITO, 2007).

Vasconcelos (1925) apresenta Boécio como o primeiro geómetra europeu a estudar o sistema numérico indiano, sem sucesso aparente, no entanto, com uma simbólica contribuição para os estudiosos futuros. Um desses, é Gebert d'Aurillac (950 - 1003), que vive em um momento mais favorável ao conhecimento, do que Boécio, porém, a Europa ainda não se apresentava preparada para avanços significativos na matemática, pois observamos ainda, a predominância de traduções e conservação de conhecimentos e principalmente a adequação da matemática e da filosofia grega para a 
construção de um arcabouço teológico que pudesse justificar as crenças católicas, como, o princípio pitagórico que o universo teria sua formação em um princípio numérico, bem como, o milagre da criação em seis dias, haja vista, seis ser o primeiro número perfeito $^{4}$ matematicamente. Dessa forma, Gebert também não tem muito sucesso na divulgação das cifras e sistema de numeração hindus (SANTOS, 2009; BROTO, 2007).

Outro fato importante para a construção de um momento favorável a implementação das cifras indianas é a contribuição de tradutores mulçumanos e judeus na Europa, os quais, segundo Potro (2000), não foram meros tradutores, no entanto, estudiosos que contribuíram para o fortalecimento e desenvolvimento da matemática na Europa.

Dessa forma, cria-se em Córdoba um clima semelhante ao de Bagdá, formando uma série de escolas de matemáticas, astronomia, medicina e botânica, onde, já se fazia conhecido muitos dos autores árabes em todo o século IX, os quais não eram apenas estudados, mas, comentados, testados e comprovados. Dando continuidade nesses estudos, temos no século X, a Escola de Astronomia Andaluzes, a qual, têm membros importes, como Ibn al Samh e Al-Zahrawi que foram mestres da aritmética e da geometria, os quais, escreveram sobre aritmética prática e aritmética comercial e esta última foi intitulada de Al-Muawalat (POTRO, 2000).

Outros personagens que podemos apresentar como contribuintes para construção matemática na Europa, são Abraham bar Hiyya e Abraham Ibn Ezra, que de igual forma não contribuíram apenas com traduções. Temos por exemplo os trabalhos feitos por Abraham bar Hiyya de aritmética, geometria, ótica, cosmografia e astronomia que em sua maioria foram escritos em hebraico, dentre esses escritos, temos o Tratado de geometria e medições, o qual foi traduzido para o latim logo em seguida pelo seu colaborador Platón de Tívoli, Abraham bar Hiyya desenvolve seus estudos em Barcelona entre os anos de 1133 a 1145 (POTRO, 2000).

De Abraham Ibn Ezra, gostaríamos de destacar sua contribuição com o livro Cálculo de compra e venda, que posteriormente foi chamada de aritmética mercantil, com vários casos práticos. Estes conhecimentos desenvolvidos estiveram presentes em uma parte considerável dos tratados de aritmética mercantil medieval, bem como seus

\footnotetext{
4 "Matematicamente, número perfeito é aquele cuja soma de seus divisores próprios é igual a ele mesmo" (BRITO, 2007, p. 129). 
métodos, conhecimentos, esses, que foram trados posteriormente por Leonardo Fibonacci (POTRO, 2000).

\section{O primeiro trabalho europeu sobre matemática indiana e árabe}

Conforme Franco Júnior (2001), a formação do feudalismo usa material histórico do século IV - ainda em meio à crise do Império Romano (sentida de uma maneira mais forte no século III) - até o século IX, consolidando-se no período do século IX à XI, chegando à baixa idade média, quando a Europa passava por transformações e atingia o apogeu do sistema feudal. Em meio a tantas transformações, sendo estas, de cunho social, político, econômico e cultural, três influenciaram diretamente para um período de estabilidades, que são a transformação na forma de produzir, o crescimento demográfico e o renascimento comercial, os quais, puderam proporcionar um ambiente mais propício a ciência e ao câmbio de conhecimentos entre o Oriente e o Ocidente, com as rotas comerciais nacionais e internacionais (SESTITO e OLIVEIRA, 2010).

Nesse momento de aquecimento comercial polos comerciais italianos despontaram, como: Veneza, Gênova, Pisa, Amalfi, Milão e Flandres (atual Bélgica e Holanda) e entre as mais famosas feiras estavam as de Champagne. Nas cidades citadas anteriormente, destacavam-se as universidades, que a partir do século XII tornaram-se excelentes centros de ensino, pois as cidades foram transformando-se pausadamente em centros culturais cada vez menos ligados aos valores da Igreja.

É nesta ocasião que surgem alguns personagens que influenciaram diretamente ou indiretamente este período do renascimento e na produção de conhecimentos científicos. Entre estes personagens estão imperadores, reis, figuras religiosas, matemáticos, inventores, entre outros.

\footnotetext{
Quando se evoca o Renascimento do século XII, pensa-se, principalmente, no movimento de tradução e de difusão das ciências e da filosofia gregas e árabes no Ocidente latino. Com efeito, vêm imediatamente à lembrança, os nomes dos diferentes centros deste movimento na Andaluzia, em Constantinopla, nos reinos do Oriente dos cruzados, na Itália e na Sicília (RASHED, 2001, p. 1).
}

Podemos afirmar que o movimento das traduções e divulgação das ciências, bem como, da filosofia grega e árabe, foram desenvolvidas em uma dimensão social original, 
ou seja, não era de exclusividade, neste momento de renascimento, o conhecimento dos intelectuais dos mosteiros, no entanto, um movimento que encontrou lugar nas cortes reais, o que permite investimentos em estudos, bem como, na criação de universidades, onde surgem nomes como Guilherme I, no coração do século XII, Guilherme II e Frederico II (RASHED, 2001).

Em meio a estes reinados, no início do século XIII, chega a Itália Leonardo Fibonacci de suas viagens pelo norte da África, principalmente em Bejaia, na qual, seu pai foi responsável por muitos anos por uma colônia mercantil ali instalada, oportunidade essa dada pelo período de estabilidade europeu. Leonardo Fibonacci ao ir muito jovem com seu pai, se familiarizou rapidamente com o mundo do comércio, assim como, com os cálculos mulçumanos a partir de suas muitas viagens pelo Mediterrâneo, passando pelo Egito, Síria, Grécia, Sicília, sul da França e Constantinopla, o que permitiu a este matemático estudar vários sistemas aritméticos (POTRO, 2000).

Nesse momento, segundo Devlin (2012), Leonardo Fibonacci estudou a pedido de seu pai na escola do ábaco, pois considerava útil e apropriado o estudo para o filho, que provavelmente ajudaria em seus empreendimentos, que Castillo (2007), aponta como seu mentor um professor árabe, sem citar seu nome. Ali, ainda jovem, tendo contato com muitos comerciantes de diversas culturas da região mediterrânea, aprendeu técnicas matemáticas desconhecidas do ocidente (OLIVEIRA, 2013).

Assim, em 1202 apresenta em seu primeiro livro, o qual, temos conhecimento, o tão vantajoso sistema e cifras indianas, tendo como título Liber Abaci, traduzido com Livro do Ábaco ou do Cálculo, que em sua parte introdutória apresenta as cifras indianas, da seguinte forma: "O primeiro capítulo começa. São as nove figuras dos indianos 987654321 e assim, com essas nove figuras, e para elas, este é o sinal de 0 , que é chamado em árabe de zephirum, se forma qualquer tipo de número" (LEONARDO PISANO, 1857, p. 2, tradução nossa).

Este livro traz dentre outras coisas em seu conteúdo, as regras para operar com a multiplicação, adição, subtração e divisão, que de forma incomum para nós, aparece nesta mesma ordem, mas, não nos deteremos nisso neste artigo. Outra questão importante, é a explicação do valor posicional que este novo sistema apresentou, 
mostrando grandes vantagens em relação aos números romanos presente também no Liber Abaci (Potro, 2000).

\begin{abstract}
As técnicas foram então aplicadas a problemas práticos como margem de lucro, câmbio de dinheiro, conversão de pesos e medidas, parcerias e juros. A maior parte do trabalho foi dedicada à matemática especulativa - proporção (representada por técnicas medievais populares como a Regra de Três e a Regra dos Cinco, que são métodos práticos de encontrar proporções), a Regra da Falsa Posição (um método pelo qual um problema é resolvido por uma falsa suposição, depois corrigida pela proporção), extração de raízes e propriedades dos números, concluindo com alguma geometria e álgebra (ENCICLOPÉDIA BRITANNICA, sd, p. 1, tradução nossa).
\end{abstract}

Desta forma, em 1202, os algarismos hindus começaram efetivamente a sufocar da aritmética os algarismos romanos, pois Leonardo Fibonacci, acaba por ser bem sucedido em sua obra, haja vistas, suas ideias serem amplamente aceitas na Itália e posteriormente na Europa, chamando a atenção de eruditos da época como João de Palermo, assim como, da corte, como de Frederico II, que passa a ser um financiador da propagação e implementação desses tão vantajosos algarismos, bem como, do sistema numérico posicional decimal. Como consequência temos que o Liber Abaci, ofusca algumas obras importantes para o medievo, como o Al-Muawalat.

\title{
Considerações finais
}

Com o exposto, podemos mesmo que de forma parcial, fazer algumas considerações em relação a implementação dos algarismos indo-arábicos na Europa no século XIII. Dessa forma, evidenciaremos alguns pontos. O primeiro desses, é o contraste social vivenciado pós separação do Império Romano, o qual, obscurece ambos os lados, ocasionando o insucesso de um "bum" científico com a divisão do Império e a destruição da biblioteca de Alexandria.

A partir desse momento, temos um período intenso de guerras no Oriente, mas, que não perduraram por tantas décadas. Ao passo que, surgiram alguns califas que encabeçaram um resgate científico de muitos manuscritos como os Elementos de Euclides, que por sua vez, garantiram o estudo destes na Europa. Percebemos, assim, que os grandes investimentos em estudos e traduções feitas no Oriente, contribuíram diretamente para o avanço matemático europeu anos mais tarde.

Um desses avanços são os algarismos indianos, bem como a implantação do sistema de numeração posicional decimal, aceito na Casa da Sabedoria e disseminado 
em meio ao povo árabe, que comumente faziam uso desse sistema de forma comercial ou de forma prática, passados alguns séculos ficaram conhecidos como Aritmética Comercial ou Mercantil e a Aritmética Prática, influência dessa última herdada dos hindus.

Embora Leonardo Fibonacci, não tenha sido o primeiro a estudar as cifras indianas, é dado a ele o trunfo de o primeiro matemático cristão, europeu ou medieval a implementar os algarismos indianos na Europa, o que podemos concordar em parte, pois foi o único a ter tamanho sucesso neste trabalho de trazer a matemática indiana e árabe à Europa. Essa afirmação pode ser justificada de algumas formas, no entanto, para este momento, se faz válida a reprodução contínua do Liber Abaci e a republicação desta obra em 1228, assim como, o uso desta como um manual para o uso das cifras e do sistema de numeração hindu, que de forma ordinária é chamada de algarismos indoarábicos.

Outro ponto de relevância é o despreparo europeu para a implementação das cifras indianas, seja por monopólio da Igreja ou pelo razoável conhecimento matemático, tal como, pelo interesse e necessidades particulares do Ocidente, que não permitiram o êxito antes do século XIII. Dessa forma, compreendemos a elegância e a sapiência com a qual Leonardo Fibonacci escreveu o Liber Abaci, portanto, a partir desta pesquisa inicial, podemos concluir que, o que de fato impulsionou a aceitação dos algarismos indianos, não foi apenas a brilhante estrutura construída no livro, mas sim, o cenário de estabilidade social, econômico, cultural, religioso e político, o que proporcionou o momento adequado para essa obra de Leonardo Fibonacci, o que não ocorreu no contexto em que Boécio e d'Aurillac se encontravam.

\section{Referências}

BOYER, Carl. B. História da Matemática. Tradução: Elza F. Gomide. São Paulo, SP: Edgard Blücher, 1974.

BRITO, Arlete de Jesus. Matemática na idade média: entre o místico e o científico.

Revista Brasileira de História da Matemática, Especial no 1, p. 127-141, 2007.

CASTILLO, R. M. Fibonacci: EI Primer Matemático Medieval. $2^{\mathrm{a}}$ ed. Coleção - La matemática em sus personajes. Espaha: Nivola, 2007. 
DEVLIN, K. The Man of Numbers: Fibonacci's arithmetic revolution. Volume 59, Number 5. Book Review. May, 2012

ENCICLOPÉDIA Britannica Online. Fibonacci. sd. Disponível em: https://www.britannica.com/biography/Fibonacci. Acesso em: 12 dez. 2019.

FRANCO JÚNIOR, H. A Idade Média: nascimento do ocidente. $2^{\mathrm{a}}$ ed. rev. e ampl. São Paulo, SP: Brasiliense, 2001.

GARBI, Gilberto. G. O Romance das Equações Algébricas. $3^{\text {a }}$ ed rev. São Paulo, SP: Ed. Livraria da Física, 2007.

LEONARDO PISANO. Liber Abbaci. Secundo la lezione del codice magliabrchiano, C. I, 2616, Badia Fiorentina, nº 73, Roma: 1857.

OLIVEIRA, J. J. Sequências de Fibonacci: possibilidades de aplicações no ensino básico. UFBA. Salvador, BA, 2013.

POTRO, Betsabé Caunedo. El Arte Del Alguarismo Em La Europa Medieval. In: POTRO, Betsabé Caunedo; LLAVE, Ricardo Córdoba De La. El Arte Del Alguarismo: um libro castellano de aritmética comercial y de ensayo de moneda del siglo XIV. Junta de Castlla y León, Espanha: 2000.

RASHED, Roshdi. Os Tradutores. CNRS-Paris. IV No. 6, 2001. Disponível em: www.hottopos.com/collat6/roshdi1.htm\#_ftnref12. Acesso em: 19 dez. 2019.

SANTOS, Alberto Tadeu Acaiaba dos. Das "trevas" a luz de Fibonacci: uma visão histórica. 2009. 97 f. Dissertação (Mestrado em história da ciência) - Universidade Católica de São Paulo, São Paulo, SP: 2009.

SESTITO, E. A. B.; OLIVEIRA, T. As Transformações do Pensamento na Baixa Idade Média e as Mudanças na Arte. Londrina, 2010.

VASCONCELOS, Fernando de Almeida e. História Das Matemáticas na Antiguidade. Lisboa: Livrarias Aillaud e Bertrand, 1925. 